\title{
Theoretical Framework, Case Study and Policy Implication of Cultural Capital Prompting Regional Innovation
}

\author{
Yu Jun ${ }^{1}$ Zhou Jingkun ${ }^{2, *}$ \\ ${ }^{1}$ School of Public Administration Zhejiang Gongshang University Hangzhou, China \\ ${ }^{2}$ School of Public Administration Hebei University of Economics and Business Shijiazhuang, China \\ *Corresponding author. Email: zhoujingkun@heuet. edu.cn
}

\begin{abstract}
Under the background of a new round of scientific and technological revolution and industrial reform, the role of innovation in promoting economic and social development is becoming more and more prominent, which is the key to building regional competitive advantages. Cultural capital can have a sustained and extensive positive impact on regional innovation, which can become an important focus to promoting regional innovation. Using literature studies and case studies, this paper investigated the influence mechanism of cultural capital on regional innovation. The study shows that the cultural capital at the regional level includes the value system shared by the specific regional groups which can promote wealth creation, as well as the cultural activities and its results with utility and value in the specific region. The impact of cultural capital on regional innovation is comprehensive, involving multiple aspects such as innovation subjects, innovation network, innovation input, innovation output and innovation environment. To promote cultural capital conducive to regional innovation, efforts should be made in three aspects of cultural policy: policy objectives, contents and implementation.
\end{abstract}

Keywords: culture capital, regional innovation, innovational policy

\section{INTRODUCTION}

At present, a new round of scientific and technological revolution and industrial reform is accelerating, the global competition pattern is showing new changes, and innovation is increasingly becoming an important force in promoting economic and social development. In this context, how to build a regional competitive advantage? The key is to stimulate innovation vitality and promote regional innovation. As an important driving force for regional innovation, cultural capital is generally recognized but at the same time overlooked. First, the definition of cultural capital itself is vague and implicit, lacking comprehensive definition and theoretical support. Second, the action mechanism of cultural capital on regional innovation is characterized by its complexity. Due to unable being fully explained, the influence of cultural capital on regional innovation is still a "black box". With the increasingly prominent trend of the integration of culture, economy and society, cultural capital plays an increasingly important role in regional innovation. This study starts from the connotation definition and constituent elements of cultural capital at the regional level to explore the action mechanism of cultural capital on regional innovation. Silicon Valley and shanghai as empirical cases are studied. Based on that, policy suggestions on promoting cultural capital to stimulating regional innovation are provided.

\section{DEFINITION OF CULTURAL CAPITAL AT REGIONAL LEVEL AND ITS CONSTITUENT ELEMENTS}

Since Bourdieu first proposed "cultural capital" in The Forms of Capital in 1986, it has been widely used in related research. Because the concept itself is metaphorical and open, different scholars have interpreted it from different disciplines, different levels and different emphasis. The most classic definitions are Bourdieu [1]'s interpretation based on sociology and Throssby [2]'s interpretation based on economics. Bourdieu believes that cultural capital is a concrete, materialized and institutionalized cultural endowment 
owned by individuals, which is conducive to personal development for a better social status. The concept of cultural capital based on Bourdieu's theory is limited at individual level, lacking the study of the group spillover effect of culture and its production as well as consumption. Throsby holds that cultural capital is the accumulation of cultural values contained in the assets, this accumulation can cause the constant flow of goods and services. The concept of cultural capital based on Throsby's theory extends cultural capital from individual level to group level and even regional level, but it is still limited to the influence of cultural production and consumption on culture itself. Studies on cultural capital at the regional level are rare. Representative research such as Florida interprets cultural capital as a cultural environment to attract creative talents and pays attention to the influence of culture on economy and society [3-4]. Tubadji believes that culture is a kind of meta-system, which extends Bourdieu's cultural capital from the individual level to the regional level [5-7].

In previous studies, there is still a lack of accurate definition for cultural capital at the regional level. To define the cultural capital at the regional level, it is essential to first clarify what is culture, and then to clarify two key elements-regionality and capital nature. It is not easy to identify the connotation of culture, and the difficulty mainly stems from the lack of consistency and universally recognized meaning of culture. In a specific context, culture can refer to artworks and art activities, cultural products, cultural services, cultural institutions, cultural activities, cultural industries, etc. It can also refer to language, symbols, etiquette, knowledge, traditions, concepts, customs, attitudes, beliefs, practices, lifestyles, mindsets, etc. In summary, culture mainly includes two categories: namely cultural value system and cultural activities \& their results. Regionality is an important feature of culture. Due to the differences in natural conditions and historical inheritance, the cultures from different regions show different characteristics. Region is a spatial limitation imposed on culture, culture can be studied at different regional levels such as country, province and city etc. "Capital" is one of the central concepts of economics, defined by Adam Smith as "part of property that is expected to provide income". To define "capital", the key is to understand its characteristics of "bringing value increment". Capital can bring economic benefits or more wealth.

Taking "regionality" and "capitalization" as constraints, this study defines cultural capital at regional level in two aspects. One is the value system shared by a specific regional group. This value system can promote wealth creation, so it belongs to intangible cultural capital. Common values affect the economic and social goals pursued by regional groups, how economic and social activities are carried out, and how resource elements and outputs are distributed, all of which are affecting macro and micro economic and social performance. For example, the spirit of capitalism is to be an important driver for the economic and social development in western capitalist countries. The Protestant ethics advocating freedom in gaining profit while restraining consumption encourages people to restrain consumption and make productive investment, thus promoting the accumulation of capital and wealth [8]. Traditional cultural values, business spirit/competitive spirit are important drivers to promote China's economic growth. The former mainly plays a role in influencing the accumulation of material capital, while the latter mainly plays a role by influencing technological progress and innovation [9]. Second, the cultural activities and their results with utility and value in a specific region belong to tangible cultural capital. Cultural activities and their results, such as music, literature, news, radio, film and television programs, internet information services, libraries, museums, arts and crafts, etc., have their own utility and value which can bring direct or indirect benefits. For example, a work of art has multiple values such as aesthetic value, spiritual value, social value, symbolic value and real value [10]. With the growth of cultural consumption demand, the cultural industry is considered as one of the most potential economic growth areas, and its output value and its proportion in GDP are increasing constantly. At the same time, cultural activities and their results are activities, products and services of special category, which embody and reflect specific values, providing people with a picture of the outside world, influencing people's knowledge, understanding and experience, thus playing an important role in the formation and evolution of values.

\section{THE ACTION MECHANISM OF CULTURAL CAPITAL ON REGIONAL INNOVATION}

Since Schumpeter put forward the concept of "innovation" in 1912, due to the poor explanatory power on reality, the early linear models have been replaced by nonlinear models. These models include national innovation system, new knowledge production model/model 2, innovation network, regional innovation system, triple helix model, $\mathrm{N}$ - helix model, open innovation, collaborative innovation and innovation ecosystem etc. With the evolution of innovation paradigm, the understanding of regional innovation is being deepened. Based on the theory of regional innovation system and innovation ecosystem, and referring to the research of Wang Kai and Zou Xiaodong [11], Adner \& Kapoor [12], regional innovation can be regarded as a system with certain geographical space and open boundary, involving many elements such as innovation subjects, innovation network, innovation input, innovation output and 
innovation environment etc. The influence of cultural capital on regional innovation is not from one dimension, but involves all aspects of regional innovation, as shown in Figure 1.

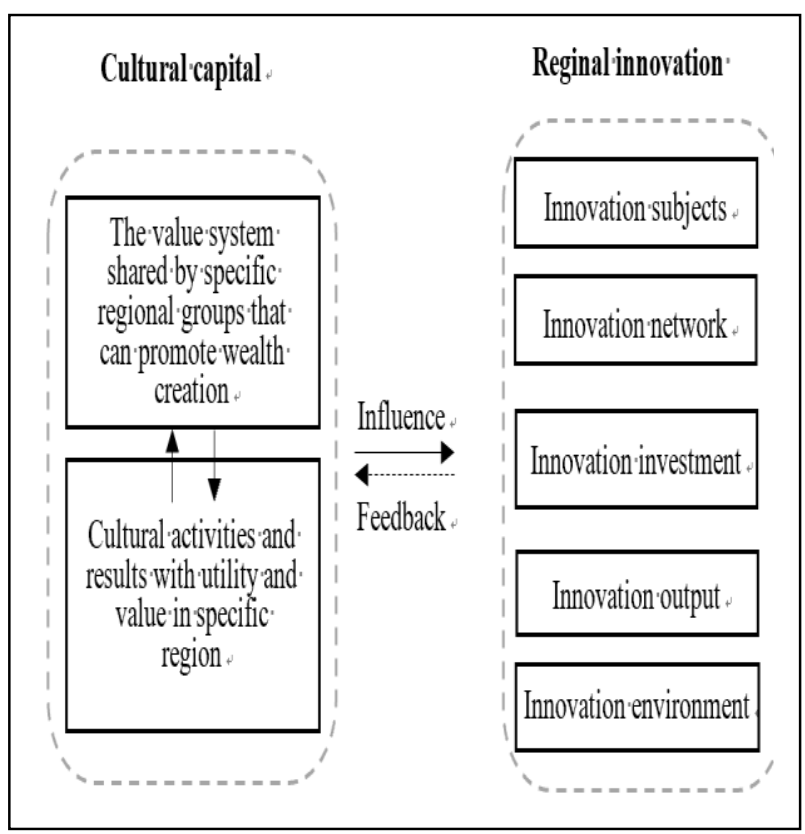

Figure 1. The action mechanism of cultural capital on regional innovation.

\subsection{Cultural capital and innovation subjects}

The scale and structure of element agglomeration is an important way for a region to gain innovative advantages [13]. Among many elements, human factor is the key. With the intensification of inter-regional competition, innovative talents have become the urgent need of regional development. The fruit of innovation is inseparable from the input of human capital (intellectual capital). From the practice in various countries, the competition for innovative talents is like a war without smoke of gunpowder. various talent platforms, talent policies and talent plans have become tools for regions gathering innovative talents. Cultural capital is also an important foundation and boost for regions gathering innovative talents.

From the perspective of the cultivation of innovative talents, the cultural environment of freedom, tolerance, equality and respect, seeking truth and being pragmatic, pioneering and enterprising is conducive to the cultivation of innovative talents. Compared with the investment in education and infrastructure, the influence on cultural environment is implicit and subtle. The cultural environment of freedom, tolerance, equality and respect is conducive to cultivating individual innovative consciousness and innovative personality. Emphasizing authority and hierarchy, individual obedience and consistency, can only cultivate people who are conservative and lack individuality, without knowledge of change and creation, unable to question and explore.
The cultural environment of seeking truth, being pragmatic and pioneering is conducive to cultivating individual innovative spirit and capability. Impetuousness, utilitarianism and not daring to be the first are obstacles to generate first-class innovation results. Innovation is an arduous and long-term process, which requires abandoning the mentality for quick success and instant benefit, and constantly trying new methods and models. From the perspective of attracting and retaining innovative talents, cultural capital is an important influencing factor at regional level, and a tolerant, diverse and open cultural environment is more likely to be favored by innovative talents. A study on the attraction for technical talents in Shanghai and Guangzhou found that economic factors could not fully explain the concentration of talents, while urban cultural character played a leading role in the flow and concentration of talents [14]. Most innovative talents advocate individuality, freedom and self-realization, tolerance, diversity and open cultural environment, which breaks down the barriers for accepting and absorbing heterogeneous things and creates favorable conditions for the gathering of innovative talents. In addition, with the improvement of the demand level, people pay more attention to the livability of the region, the demand for cultural consumption is constantly rising. The profound historical and cultural heritage, rich cultural products and services, and complete cultural facilities have also significantly enhanced the attraction of the region to innovative talents.

\subsection{Cultural capital and innovation network}

Innovation network refers to the network structure composed of innovation subjects and their relationships [15]. Innovation network is of great significance to optimize the allocation of regional innovation resources and enhance regional innovation capability, which helps to give full play to professional advantages, reduce transaction costs, promote innovation diffusion and promote the formation of network-based continuous innovation [16]. A good innovation network requires close communication and cooperation among innovation subjects, and cultural capital is an important condition to promote the formation of good relations among innovation subjects.

The cultural environment advocating trust, integrity and respecting others is the foundation of virtuous interaction among regional innovation subjects, which helps promote the flow and sharing of innovation resources [17-18]. There are potential risks in communication and cooperation among innovation subjects, various conflicts and contradictions may occur, which may be due to lack of trust or cognitive differences between different parties, or due to malicious deception, breaking of promise and breach of contract, etc. Therefore, mutual trust is the basic 
prerequisite. The higher the degree of trust, the more likely and smoothly the communication and cooperation will take place, which will help reduce various costs for coordination, transaction and management, thus improving innovation performance. Integrity is the prerequisite of trust. Only by integrity can we gain mutual trust among innovation subjects, otherwise even if trust is established, it will be destroyed finally. Sometimes cognitive differences are inevitable. When differences exist, what is needed is mutual respect and seeking common ground while reserving differences. Innovation subjects are always influenced by regional culture. The values of trust, integrity and respecting others can be internalized into innovation subjects' own codes of conduct and expectations for others, thus enhancing the willingness for cooperation and exchange among innovation subjects, realizing cooperation and exchange, forming a virtuous circle through practice and experience. In addition, the openness and inclusiveness of regional culture will also affect the innovation network. The excessive embeddedness of culture will bring obstacles to the expansion of innovation network, only targeting local innovation subjects and innovation resources, resulting in exclusion of outsiders. The values of openness and inclusiveness can help break through this limitation, acknowledging and encouraging innovation subjects to seek external cooperation and exchange, introducing and utilizing external innovation resources, actively expanding innovation networks. Under the background of intensified competition and globalization of resource allocation, external cooperation and exchanges are becoming more and more important, and the openness and inclusiveness of regional culture have a more prominent influence on innovation networks.

\subsection{Cultural capital and innovation investment}

Innovation investment (expenditure, human resources, etc.) are the prerequisite for carrying out innovation activities and the direct source for promoting regional innovation. Innovation investment is characterized by spatial heterogeneity. There is a big gap in terms of innovation investment intensity in different regions, so there is a tendency of concentration of innovation investment in terms of its geographical distribution [19]. Lack of innovation consciousness is an important reason for innovation investment. How to guide and encourage innovation investment? Cultural capital can play a positive role.

Entrepreneurship, innovation and entrepreneurship culture are helpful to stimulate innovation activities and increase innovation investment [20-21]. Resources are scarce. Under the condition of limited resources, how to allocate financial resources, human resources and other essential resources for different purposes are crucially influenced by the cognition and preference of decision- makers. Only when decision-makers attach importance to innovation can more essential resources be invested in innovation. Entrepreneurship was first proposed by Richard Cantillon in 1775. It is a typological trait of managers, covering innovation, adventure, pioneering, forward-looking, pursuit of excellence, craftsmanship, sense of mission and responsibility, etc. It emphasizes taking risks under uncertain conditions, daring to be the first, breaking through old mindsets, models and practices, carrying out innovative practices, developing new products, providing new services and developing new technologies to take the advantage of changes and innovations in the market to find profit opportunities and achieve success. Managers with entrepreneurial spirit are more likely to put more essential resources into innovative activities. A strong cultural environment of innovation and entrepreneurship helps to cultivate and attract managers with entrepreneurial spirit and support them to carry out innovation and entrepreneurship activities, leading to relatively active regional innovation activities and relatively more investment in innovation. Innovation and entrepreneurship culture affect not only managers with entrepreneurial spirit, but also the public. Advocating the values of innovation and entrepreneurship influences the public's attitude towards innovation and entrepreneurship, helping cultivate and stimulate the public's sense of innovation, mobilizing the public's enthusiasm, so as to participate more in innovation activities, forming a trend of "mass entrepreneurship and innovation".

\subsection{Cultural capital and innovation output}

There is a complicated transformation process from innovation input to innovation output. Innovation investment may not necessarily bring innovation output: innovation activities may result in failure and its probability is even quite high. The input-output ratio in innovation may be unsatisfactory, resulting in lower returns. Even if we were to remove the influence of innovation input, there are also great regional differences in innovation output. This difference is caused by many factors including cultural factors.

Innovation is a multi-stage process, which follows the division of Glynn [22]. The following examines the action mechanism of cultural capital in the stages of invention and implementation for innovation respectively. In the stage of invention, innovation is mainly basic and applied research, and creativity plays a key role. Cultural factors influence creativity, with different influences on creative products, individuals, processes and environment [23]. The cultural orientation to freedom, independence and respecting individuality emphasizes overcoming habitual thinking, breaking conventions and practices, freely expressing individual views, tolerating new ideas and non-compliant 
behaviors, which is conducive to stimulating individual creativity and innovation. Diversified and open culture can become the source for individual creativity. Through communication, brain storming and learning from others, individual creativity can be enhanced, generating valuable innovations. In addition, innovation can benefit from the development of culture and art. To some extent, culture and art are the tools for reflecting on society or reflection of social life [24]. Culture and art can become the object of innovation as well as the inspiration for innovation. From this perspective, cultural capital in the sense of cultural activities and activity results also plays a positive role in the creation of innovation. In the implementation stage of innovation, innovation mainly includes experimental development and subsequent commercialization and industrialization etc. In the strong culture environment of innovation and entrepreneurship, innovation activities tend to be more active, leading to a better healthy mechanism and conditions for the transformation of innovation results, involving well-functioning incubators, science \& technology consulting and evaluation, technology transaction and other scientific and technological intermediaries, as well as angel investment and venture capital that provide financial support. Therefore, a good innovation results will not be shelved, avoiding trapped in its initial stage.

\subsection{Cultural capital and innovation environment}

The regional innovation environment includes not only hard environments such as infrastructure, market system, financial system, education and scientific research system, but also soft environments such as social \& cultural environment, institutional environment and learning environment that affect the cognition and behavior of innovation subjects [25-26]. Good innovation environment not only provides all-round support and guarantee for innovation activities, but also promotes the spread of innovation, and can encourage innovation subjects to carry out innovation activities. Cultural capital is an important component of the innovation environment, and it also has a beneficial impact on other components of the innovation environment.

Cultural capital, as a soft environment for innovation, has been explored in the previous discussion. Advocating values such as innovation, adventure, freedom, tolerance, independence, personality, trust, integrity, respect, openness and pluralism is beneficial to innovation subjects, innovation network, innovation input and output. The guiding role of values makes individuals or groups in the region form relatively consistent cognitive and behavioral patterns. Innovation is regarded as a behavior worthy of acknowledgement and encouragement, and various factors hindering innovation are effectively restrained, thus fully stimulating the innovation enthusiasm of individuals or groups in the region, integrating innovation into all aspects of regional economic and social life. The development of cultural undertakings and cultural industries better meets the spiritual and cultural needs of the public, promoting the livability of the region, helping gather innovative resources, providing inspiration for innovation. Various cultural resources also have potential and value for innovative development and utilization. Cultural activities and their results influence people's cognition of the outside world. They are conducive to advocating and strengthening the value of innovation \& entrepreneurship in their matched cultural activities and their results, being accepted and recognized by people and becoming the value system shared by regional groups. In addition, cultural capital also influences government policies, market systems, education and scientific research systems, etc. For example, formulating innovation policies is closely related to the government's perception of innovation. Whether the market is healthy and active is influenced by the market subjects' sense of integrity \& business spirit, and the development of education and scientific research is influenced by the public's emphasis on knowledge and education.

\section{ICASE STUDY ABOUT THE INFLUENCE OF CULTURAL CAPITAL ON REGIONAL INNOVATION}

Silicon Valley is a successful example of regional innovation, and it is the object being imitated and followed by many countries and regions. Shanghai is one of the leading cities in China in terms of innovation capacity. Based on these two typical regional cases, this paper discusses how cultural capital affects regional innovation in practice. Comparing the two cases, we can find some similarities. Cultural capital has a continuous and great influence on regional innovation. The value system conducive to innovation and entrepreneurship has effectively improved the innovation enthusiasm of innovation subjects and promoted regional innovation and entrepreneurship activities. Cultural activities and their results have improved the livability and attractiveness of the region, advocating and strengthening the value system conducive to innovation and entrepreneurship, facilitating the gathering of innovative elements, especially innovative talents.

\subsection{Silicon Valley}

Silicon Valley, located in the southern part of San Francisco Bay Area in northern California, is a center of high-tech innovation and scientific development. It has gathered the headquarters of 39 Fortune 1000 companies and thousands of startups, attracting many 
talents to innovate and start businesses every year. There are two levels of cultural capital owned by Silicon Valley. One is the Silicon Valley culture, which is called "the soul of Silicon Valley", covering the value system of innovation, encouraging adventure, pioneering \& enterprising, tolerance \& failure, equality $\&$ relaxation, interdependence, flexibility and pluralism [27-29]. Second, the explicit form of Silicon Valley culture, including hardware facilities and works of art that integrate and embody Silicon Valley culture.

Silicon Valley culture and its explicit form have brought constant driving force to the innovation and development of Silicon Valley. From the perspective of the influence on innovation subjects, the culture of innovation and risk-taking has created a strong atmosphere of innovation and entrepreneurship, emphasizing entrepreneurship, supporting and encouraging innovation \& entrepreneurship, attracting innovative talents with rich creativity, preference for risk-taking and challenges. Every year, a large number of new start-ups are established, innovation and entrepreneurship activities are very active, successful entrepreneurs become benchmarks, innovation stories are inspiring, innovation and entrepreneurship become people's pursuit and dream, and people have great enthusiasm for innovation and entrepreneurship, realizing their own value in adventure and challenge. From the perspective of its influence on innovation network, the culture of equality \& relaxation, interdependence helps encourage communication and cooperation among innovation subjects and enhance innovation ability through communication and sharing. Cooperation and exchange are both internal and external. And communication and exchange can be either formal or informal. In the process of cooperation, a relationship of mutual trust has been built among different subjects. The culture of equality and relaxation makes the communication between people free from hierarchy barriers, and the flow of talents is not restricted. The strong mobility of personnel promotes the flow of other innovative elements resources such as technology, information and capital, thus realizing the optimal allocation of innovative elements resources. From the perspective of the influence on innovation investment, the culture of tolerance to failure encourages individuals to explore, try and take risks. The failure of innovation and entrepreneurship is not regarded as shame, but as accumulating experience, honing before success and contributing to the future success. Investors are willing to invest their money in entrepreneurs who have failed in innovation and startup in the past. Innovation and startup business are accompanied by high risks, and failure is inevitable. Being tolerant to failure greatly encourages investment in innovation. Although a large number of companies go bankruptcy every year in Silicon Valley, it does not hinder the incorporation of a large number of new startups. According to the report the Silicon Valley Institute for Regional Studies, in 2017, nearly 30\% of the total venture capital and $30 \%$ of angel investment in the United States were in Silicon Valley[30]. From the impact on innovation output, the flexible and diverse culture makes Silicon Valley open and inclusive. As a valley of immigrants, people from all over the world come to Silicon Valley to find jobs and start businesses, which has brought huge excellent human resources and injected lasting vitality into the development of Silicon Valley. Thanks to the collision and blending of multiple cultures, it is easy to breed new ideas and things, which are easily accepted and developed here in Silicon Valley. In 2017, the average value created by employees in Silicon Valley reached $\$ 193,454$, which was significantly higher than the average level of California and the United States[30]. From the perspective of the impact on the innovation environment, the hardware facilities and art works integrated into Silicon Valley culture also play a positive role. For example, the office environment of Google headquarters in Silicon Valley has always been praised, attracting Internet practitioners all over the world. The unconstrained design style, the ubiquitous high-tech equipment, the Android version statues, dinosaur skeleton statues and other displays all reflect Google's innovative culture. Then there are films and TV productions like Silicon Valley, which is a comedy that tells the story of innovation in Silicon Valley, reflecting the scene of starting business, working and living in Silicon Valley. Besides its own commercial value, it also advocates the culture of Silicon Valley.

\subsection{Shanghai}

Shanghai is the core city among the Yangtze River city cluster in China, and it is one of the regions with the fastest economic development and the strongest innovation capability and vitality in China. The cultural capital owned by Shanghai involves two aspects. First, its unique Shanghai-style culture, including a value system that is inclusive, open and pluralistic, encouraging innovation and pioneering [31-33]; Second, a relatively sound public cultural service system and a large-scale cultural industry.

Shanghai-style culture, its public cultural service system and cultural industry are the source of city soft power, which plays an important role in the construction of Shanghai's urban innovation capability. From its influence on innovation subjects and innovation network, Shanghai-style culture is both inclusive and open. Since the 1920s, Shanghai has been known as the "paradise for adventurers". Thanks to its location advantage as a land and water hub, Shanghai has become an area with a concentrated immigrant population. People from all over the world, with different nationalities and races, come to work and live 
in Shanghai. At the same time, they bring their own unique cultures and customs from all over the world. Different cultures interact and merge here, contributing to the inclusive characteristics of Shanghai culture. The culture of inclusion has made Shanghai attractive to innovative resources and gathered a large number of innovative talents at home and abroad. Openness and diversity are interdependent with relaxing and forgiving, accommodating to new ideas and new things, and promotes the emergence and dissemination of innovation. From the influence on innovation input and its output, Shanghai-style culture has strong creativity and pioneering. Since the reform and opening up, Shanghai has been at the forefront of institutional innovation in China, such as developing and opening Pudong, building economic center, financial center and trade center, building science and technology innovation center, and setting up Shanghai Free Trade Zone. All these undertakings are pioneering and innovative. It can also be seen in the popular culture, where people are motivated and enthusiastic about innovation and entrepreneurship, creative, risk-taking and pioneering. From the perspective of the impact on the innovation environment, cultural products, services and activities that reflect the quality and style of Shanghai are constantly being created. According to the Statistical Yearbook of Chinese Culture and Related Industries (2017), in 2016, the added value of Shanghai's culture and related industries was RMB 186.17 billion, accounting for $6.61 \%$ of GDP, ranking second in China. The prosperity and development of culture helps the publicity of city image and culture, enhancing the livability and influence of the city, improving the attraction of innovative elements, especially innovative talents.

\section{CONCLUSION}

Innovation is the inexhaustible driver for regional development, which constitutes the unrepeatable competitive advantage of the region. For the construction of regional innovation capacity, two points are particularly important. First, sustainability. Innovation is continuous and dynamic. It is imperative to promote the region to maintain its lasting innovation vitality for its innovation capacity building. Second, universality. Innovation can come from anyone and any organization. It is imperative to promote mass entrepreneurship and innovation for regional innovation capacity building. Cultural capital can have a continuous and extensive positive influence on regional innovation. Promoting cultural capital conducive to regional innovation may not improve regional innovation capability overnight, but in the long run, it is able to sustainably increase the attractiveness of the region to innovation factor resources, helping improve regional innovation input and output, and at the same time guiding the formation of a good environment for innovation and entrepreneurship, enhancing people's enthusiasm for innovation and entrepreneurship, and boosting regional innovation activities. This study has clear policy implications, and it is imperative to optimize and improve the corresponding innovation policies to promote the cultural capital beneficial to regional innovation.

\subsection{Policy objectives}

From the innovation policies introduced by different localities in recent years, there are few discussions and targeted policies related to culture, so there is a lack of clarity on the importance of enhancing cultural capital conducive to regional innovation at a higher and deeper level. For any regional development, it is becoming more and more important to promote cultural capital which is conducive to regional innovation. It is imperative to pay more attention to the cultural capital that is conducive to regional innovation, and recognize it as an important tool and key force in enhancing regional innovation capacity and performance. We shall include the promotion of cultural capital conducive to regional innovation in the regional innovation policy objectives. It is not optional, shouting slogans or cherries on top, but to really attach importance to and emphasize the cultural factors. Of course, this also requires further clarification and definition of the connotation and extension of cultural capital conducive to regional innovation and its action mechanism at the theoretical level.

\subsection{Policy content}

Overall, the discussion related to culture in the current innovation policy lacks concrete and operable methods and tools. Cultural capital at the regional level involves two aspects: value system, cultural activities and activity results, so the policy content promoting cultural capital conducive to regional innovation should also cover these two aspects. First, establishing and communicating a value system conducive to regional innovation. Publicity \& promotion, theme activities, cultural environment building, incentive mechanism and other methods can help guide the formation of regional culture conducive to innovation and entrepreneurship. We shall recognize that culture has the characteristics of natural growth. In addition to actively guiding its future development, carrying on regional cultural traditions is also a must. Second, promoting regional cultural activities and their results are conducive to the value system for regional innovation. Cultural symbols are dependent on the corresponding material aspects, so it is necessary to carry out and promote cultural activities beneficial to regional innovation, and to plan and develop cultural works conducive to regional innovation. At the same time, we shall start from the needs of innovative talents, improve the regional public 
cultural service system and promote the development of cultural industry thus enhancing the attraction of the region to innovative talents.

\subsection{Policy implementation}

From the perspective of policy implementation, we shall first pay attention to the synergy of policies. Innovation policies to enhance cultural capital conducive to regional innovation should be coordinated with other related policies such as cultural, education, science and technology policies etc. Second, we shall pay attention to the long-term effects of policies. The effects of policies to enhance cultural capital conducive to regional innovation have a slow-release process and are not immediate but cumulative and progressive. The corresponding policy should maintain a certain degree of stability, and the assessment of policy performance shall also consider its time difference and lagging nature. Finally, we shall pay attention to the dynamic nature of policies. It is a dynamic and continuous process to promote cultural capital which is conducive to regional innovation, and the corresponding policies shall be adjusted and optimized according to the actual situation and needs of regional development.

\section{REFERENCES}

[1] Bourdieu P. The forms of capital. In: Richardson J $\mathrm{G}$, ed. Handbook of theory and research for sociology of education [M]. New York: Greenwood Press, 1986: 241-258

[2] Throsby D. Cultural capital [J]. Journal of Cultural Economics, 1999, 23(1/2): 3-12.

[3] Florida R L. Bohemia and economic geography [J]. Journal of Economic Geography, 2002, 2(1):55-71.

[4] Cooper R N. The flight of the Creative Class: the new global competition for talent by Richard Florida[J]. Foreign Affairs, 2005, 84(5):170.

[5] Tubadji A. Culture - based development: empirical evidence for Germany [J]. International Journal of Social Economics, 2012, 39(9):690-703.

[6] Tubadji A, Pelzel F. Culture based development: measuring an invisible resource using the PLS-PM method $[\mathrm{J}]$. International Journal of Social Economics, 2015, 42(12):1050-1070.

[7] Tubadji A, Gheasi M, Nijkamp P. Immigrants' Socio-Economic Achievements and Cultural Diversity: Economic Effects of Individual and Local Cultural Capital [J]. International Journal of Manpower, 2017, 38(5):712-728.
[8] Max Weber. The Protestant Ethic and the Spirit of Capitalism [M]. Shanghai: Shanghai People's Publishing House, 2010: 145.

[9] Li Juanwei, Ren Baoping. New Power of China's Economic Growth: Traditional Culture or Business Spirit? -Theoretical and Empirical Research from the Perspective of Cultural Capital [J]. Economic Science, 2013, (4): 5-15.

[10] Throsby. Economics and Culture [M]. Beijing: China Renmin university Press, 2011: 30-31.

[11] Wang Kai, Zou Xiaodong. From the National Innovation System to the Regional Innovation Ecosystem-a New Perspective of Collaborative Innovation between Industry and University [J]. Studies in Dialectics of Nature, 2016, (9): 97-101.

[12] Adner R, Kapoor R. Innovation ecosystems and the pace of substitution: Re - examining technology S - curves [J]. Strategic Management Journal, 2016, 37(4):625-648.

[13] Chang C L, Oxley L. Industrial Agglomeration, Geographic Innovation and Total Factor Productivity: The Case of Taiwan [J]. Mathematics \& Computers in Simulation, 2009, 79(9):27872796.

[14] Lun Rui. Innovative Culture, Scientific Spirit and the Attraction to Urban Technical Talents [J]. Scientific Research, 2009, 27 (2): 170-175.

[15] Powell W W. Network Dynamics and Field Evolution [J]. American Journal of Sociology, 2015, 110(4):1132-1205.

[16] Liu Jian. The Essence and Significance of Regional Innovation Network [J]. Contemporary Economic Research, 2006, (1): 36-39.

[17] Ma Ru. Analysis of the Impact of Social Capital on Regional Innovation in China - Based on a Spatial Knowledge Spillover Perspective [J]. Soft Science, 2017, 31 (2): 29-32.

[18] Bialk-Wolf A, Pechlaner H, Nordhorn C. The role of culture in building regional innovation systems and its impact on business tourism - The case of the Nuremberg Metropolitan Region [J]. Poznan University of Economics Review, 2013, 13(4):111129.

[19] Wan Yong. Research on the Spatial Distribution of China's Investment in Science and Technology Innovation and its Optimization Measures-Taking R\&D Investment as an Example [J]. Economic System Reform, 2013, (1): 42-45.

[20] Ibata - Arens K. The Kyoto Model of Innovation and Entrepreneurship: Regional Innovation 
Systems and Cluster Culture [J]. Prometheus, 2008, 26(1):89-109

[21] Ni Chunhu. Creating a Good Environment for Innovation and Entrepreneurship [J]. People's Forum, 2017, (29): 90-91.

[22] Glynn M A. Innovative genius: A framework for relating individual intelligences to innovation $[\mathrm{J}]$. Academy of Management Review, 1996, 21(4):1081-1111.

[23] Zhang Wenjuan, Chang baorui, Zhong Nian, etc Culture and Creativity: Analysis based on $4 \mathrm{P}$ Model [J]. Journal of Beijing Normal University, 2016, (2): 25-36.

[24] Oliveira J A D, Silva A J D. Arts, Culture and Science and Their Relationships [J]. Systemic Practice \& Action Research, 2011, 24(6): 565-574.

[25] Ge wenqi. On Regional Economic Development and Regional Innovation Environment [J]. Academic Research, 2002, (1): 60-63.

[26] Ye Dan, Huang Qinghua. Research on the Influence of Regional Innovation Environment on Innovation Efficiency of High-tech Industry Based on DEA-Malmquist Method [J]. Macroeconomic Research, 2017, (8): 132-140.

[27] Saxenian A. Regional Advantage: Culture and Competition in Silicon Valley and Route 128 [J]. Contemporary Sociology, 1995, 32(1): 100-101.

[28] Zhang Xiu'e, Qi Weihong, Fang Zhuo. Research on Entrepreneurship Ecosystem Environment in Silicon Valley [J]. Science and Technology Progress and Countermeasures, 2016,33 (18): 5964.

[29] Liu Gang, Zhang Zaisheng, Wu Shaoyu. Research on the Formation Mechanism and Operation Mode of Innovation Ecosystem — Based on the Comparative Analysis of Silicon Valley and Tianjin High-tech Zone [J]. Scientific Management Research, 2017,35 (6): 32-35.

[30] The Silicon Valley Institute for Regional Studies. the Silicon Valley Index [R]. 2018.

[31] Lun Rui. Innovation Culture, Scientific Spirit and The Attraction to Urban Technical Talents [J]. Scientific Research, 2009,27 (2): 170-175.

[32] Wang Wei, Sun Pinjie. The Development of Shanghai Culture and Rise of China's Soft Power [J]. Journal of Shanghai University, 2007,14 (1): 75-78.

[33] Xu Qingquan. The Main Characteristics of The Development of Shanghai-Style Culture and the
Dimension of The Times [J]. Shanghai Culture, 2017, (6): 29-38+125. 